\title{
Ocorrência de Ironstones no Devoniano da Bacia do Paraná
}

\author{
Leonardo Costa de Oliveira ${ }^{1} \&$ Egberto Pereira $^{2}$
}

\begin{abstract}
Resumo A origem de ironstones oolíticos, preservados no registro sedimentar, tem sido assunto de muitos debates nas últimas décadas. Tais depósitos formam importantes unidades no registro paleozoico e a determinação de seu significado sedimentológico e estratigráfico é fundamental na interpretação do contexto deposicional dessas sucessões sedimentares. Os ironstones oolíticos da Formação Ponta Grossa estão intimamente associados aos limites de sequência e subsequentes superfícies transgressivas. Essas unidades foram descritas a partir da análise de um furo de sondagem localizado no noroeste da Bacia do Paraná. Esses ooides teriam sido depositados sob baixa taxa de sedimentação em condições marinha rasas, intercalados a eventos transgressivos episódicos, os quais retrabalhariam esses sedimentos. A descrição da evolução diagenética destes ooides de ferro foi feita através de estudos petrográficos e análises de difratometria de raios-X e de microscopia eletrônica de varredura (MEV). Tais análises indicam que a mineralogia dos ooides foi gerada durante a eodiagênese. Os ironstones são constituídos, principalmente, por ooides e cutículas de bertierina, cimento de siderita preenchendo os poros e por calcita ferrosa tardia. O intervalo oolítico estudado apresenta-se no furo de sondagem com laminação ondulada truncada. Esse aspecto faciológico reforça a ideia de que as condições necessárias para o desenvolvimento dos depósitos de ironstones oolíticos foi o intenso retrabalhamento sedimentar, unido às baixas taxas de acumulação.
\end{abstract}

Palavras-chave: ironstone, diagênese, estratigrafia de sequências, Bacia do Paraná.

\begin{abstract}
Ironstone ocurrence in the Devonian of the Parana Basin. The ooidal ironstones origin preserved in the sedimentary record has been subject of many discussions in the last decades. These deposits form prominent units in the Paleozoic record, and an assessment of their sedimentological and stratigraphic significance is essential for the interpretation of sedimentary successions. The ooidal ironstones from the Ponta Grossa Formation are associated with a major sequence boundary and subsequent transgressive surface. These ooidal ironstones were described in a borehole located in the north part of Paraná Basin. They were interpreted as they had been deposited under conditions of low net sediment accumulation with episodic storm events reworking the sediments, in a shallow-marine environment. Through petrographic studies, X-ray diffraction, and scanning electron microscope (SEM) analyses made possible the depiction of the ooidal ironstones diagenetic evolution. Such analyses indicate that the ooidal ironstone mineralogy was formed during eodiagenesis. The ironstones are dominated by berthierine ooids and grain-rimming and pore-filling siderite, with later ferroan calcite. The ooidal interval observed in the borehole presented wave cross lamination. This faciologic aspect reinforces the idea that the conditions required for the development of the ironstones deposits were intense sediment reworking and slow net sediment accumulation rates.
\end{abstract}

Keywords: ironstone, diagenesis, sequence stratigraphy, Paraná Basin.

INTRODUÇÃO Ooides ferruginosos são recorrentemente descritos em depósitos sedimentares paleozoicos. Estes depósitos são identificados, ao longo de uma ampla área de ocorrência no sudoeste europeu, associados a sequências ordovicianas, depositadas em contexto de plataforma (Young 1992). Em todos os depósitos analisados por Young (1992), estes sedimentos são posicionados em um contexto transgressivo, relacionado ao aumento do nível do mar e posicionados próximo à superfície de inundação máxima, em um arcabouço de sequência de segunda ordem.

Na plataforma sul-americana ooides ferruginosos foram descritos por Orué (1996), o qual os identificou em afloramentos de idade Aeroniano (Eolandoveriano) na região do Arco de Assunção. Ooides ferruginosos foram também descritos em depósitos pré-cordilheiranos associados à Formação Dom Bráulio por Astini (1998). Segundo Astini (1998), os ooides descritos são de composição chamosítica e em menor escala goetítica. Esses depósitos foram interpretados como originados em ambientes litorâneos rasos de alta energia. Sua origem, de acordo com Astini (1998), está associada a variações do nível do mar no contexto de um evento transgressivo mundialmente conhecido de idade Landoveriana (base do Siluriano).

Na Bacia do Paraná, Pereira (2000) também reconheceu, no furo de sondagem RD-116, localizado na porção paraguaia da bacia, depósitos oolíticos 


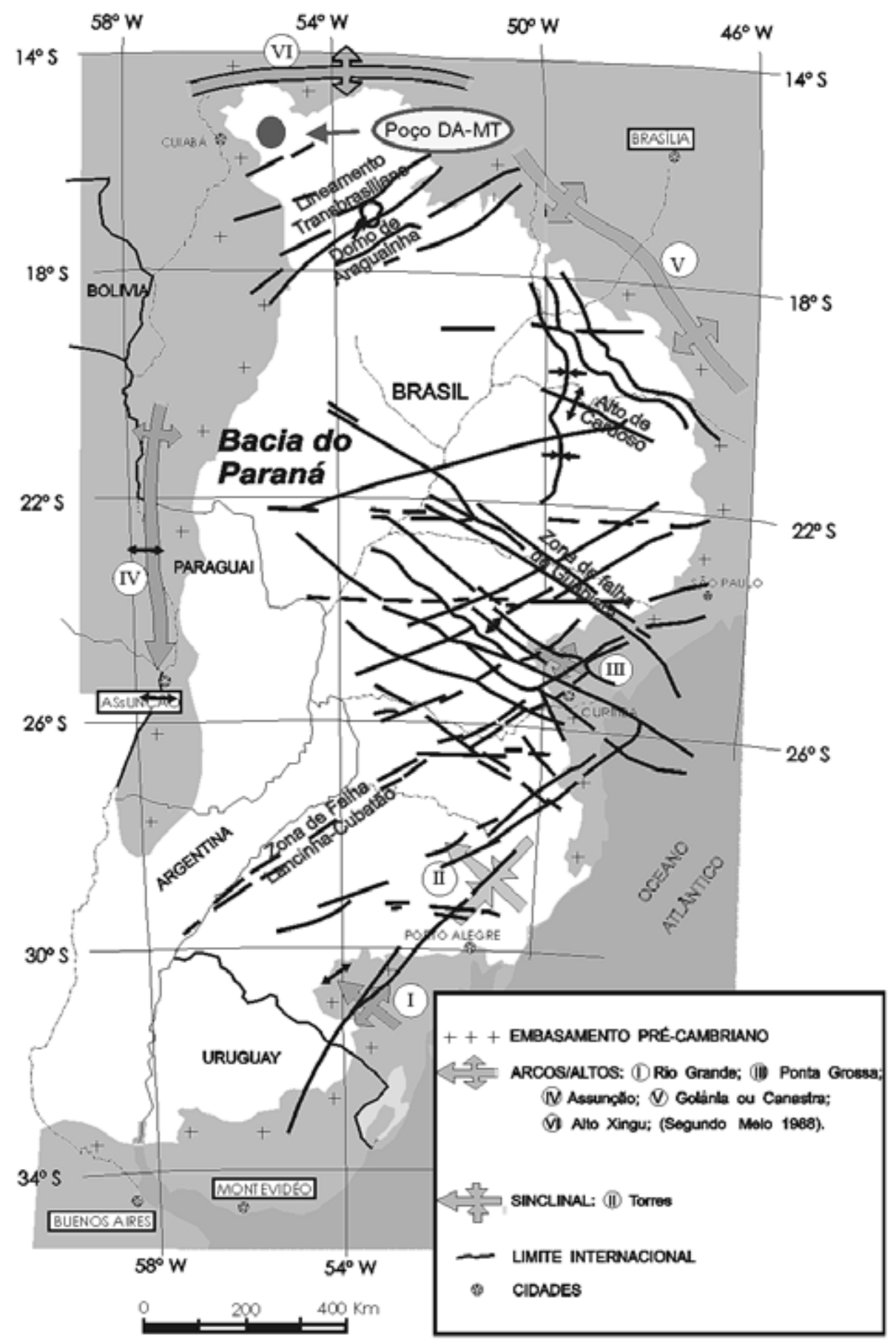

Figura 1 - Mapa de localização da área de estudo, destacando-se as feições estruturais mais significativas da Bacia do Paraná (fonte: Grahn et al. 2002).

ferruginosos posicionados na base de uma superfície transgressiva vinculada ao evento transgressivo Aeroniano (Eolandoveriano).

Recentemente, Freitas-Brazil (2004) identificou para o devoniano superior da Bacia do Paraná ooides de bertierina, que marcam nitidamente a instalação de um progressivo afogamento da bacia, em uma escala de sequência de $3^{\mathrm{a}}$ ordem, durante o intervalo Givetiano/Frasniano. Foram também identificados pela autora ooides de goetita, produzidos a partir da oxidação dos ooides de bertierina, que demonstram a alternância de condições de anoxia, durante momentos de afogamento, que favorecem a formação dos ooides de bertierina, com a instalação de zonas óxicas na bacia, que podem ter sido produzidas por processos de regressão forçada.

$\mathrm{Na}$ literatura há diferentes modelos advogados para a gênese dos ooides ferruginosos. Segundo Sturesson et al. (1999), o modelo genético mais frequente para a formação desses depósitos inclui uma associação entre o transporte fluvial até o mar dos produtos do intemperismo laterítico e a variação relativa do nível do mar. Esses autores levantam a hipótese de uma origem 
vulcânica para os depósitos oolíticos e os descrevem no interior de ciclos de shallowing-upward limitados por superfícies transgressivas. Embora o modelo genético não seja consensual, a maioria dos autores (p.ex. Astini, 1998) admite que a estrutura concêntrica, com distintas composições, representa variações químicas relacionadas ao ambiente deposicional. Nos momentos de transgressão, as condições de anoxia favorecem o aumento da concentração de ferro ferroso $\left(\mathrm{Fe}^{2+}\right)$, sendo que, durante os processos de oxigenação, ocorrem as condições de precipitação.

Área de estudo Os arenitos (ironstones) estudados neste trabalho são da seção devoniana da Bacia do Paraná, observados na região de Dom Aquino, no estado do Mato Grosso (Fig. 1).

Os mesmos foram amostrados a partir de furo de sondagem realizado pelo Departamento de Estratigrafia e Paleontologia da UERJ, posicionado entre os paralelos $14^{\circ} 00^{\prime}$ e $18^{\circ} 00^{\prime}$ latitude sul e os meridianos $54^{\circ} 00^{\prime}$ e $55^{\circ} 00^{\prime}$ de longitude oeste, nas proximidades da região de Dom Aquino (MT). Todas as amostras, bem como o testemunho onde as mesmas foram coletadas encontram-se disponíveis no Laboratório Geral de Processamento de Amostras da Faculdade de Geologia da Universidade do Estado do Rio de Janeiro (LGPA-FGEL-UERJ).

Contexto estratigráfico e deposicional Os sedimentos estudados neste trabalho estão englobados na Supersequência Paraná, definida por Milani (1997), a qual engloba os depósitos associados às formações Furnas e Ponta Grossa.
A supersequência Paraná é representada por uma espessa sucessão de arenitos litorâneos e marinhos da Formação Furnas e pelos folhelhos marinhos com intercalação de arenitos regressivos da Formação Ponta Grossa. A evolução sedimentar da mesma documenta um ciclo transgessivo-regressivo de sedimentação que iniciou com os depósitos fluviais, transicionais e costeiros da Formação Furnas (Bergamaschi 1992).

Segundo Bergamaschi \& Pereira (2001), o pacote sedimentar Devoniano da Bacia do Paraná pode ser subdividido em seis sequências de $3^{\mathrm{a}}$ ordem (Fig. 2). A Formação Furnas compreenderia a sequência A dos referidos autores e a Formação Ponta Grossa englobaria as sequências $\mathrm{B}, \mathrm{C}, \mathrm{D}, \mathrm{E}$ e $\mathrm{F}$, as quais se depositariam sobre a Formação Furnas, segundo a maioria dos autores, em contato concordante do tipo transicional em quase toda extensão da bacia. No entanto, a relação de contato entre as formações Furnas e Ponta Grossa é controversa, sendo a mesma caracterizada de forma distinta por diferentes autores. Recentemente, Grahn et al. (2010a) e Grahn et al. (2010b) apresentaram uma discussão detalhada sobre essa relação de contato nas sub-bacias de Apucarana e de Alto Garças.

De modo geral, a Formação Ponta Grossa é composta por folhelhos cinzentos, micáceos, finamente laminados e localmente carbonosos; e por folhelhos sílticos, com siltitos e arenitos de granulação fina a muito-fina subordinados, depositados em ambiente marinho pouco profundo (Schneider et al. 1974). Este ambiente, segundo Milani (2004), estaria associado a um grande golfo com efetiva conexão com as incursões oceânicas do Panthalassa a oeste, cujo paleoambiente marinho plataformal é atestado por ampla

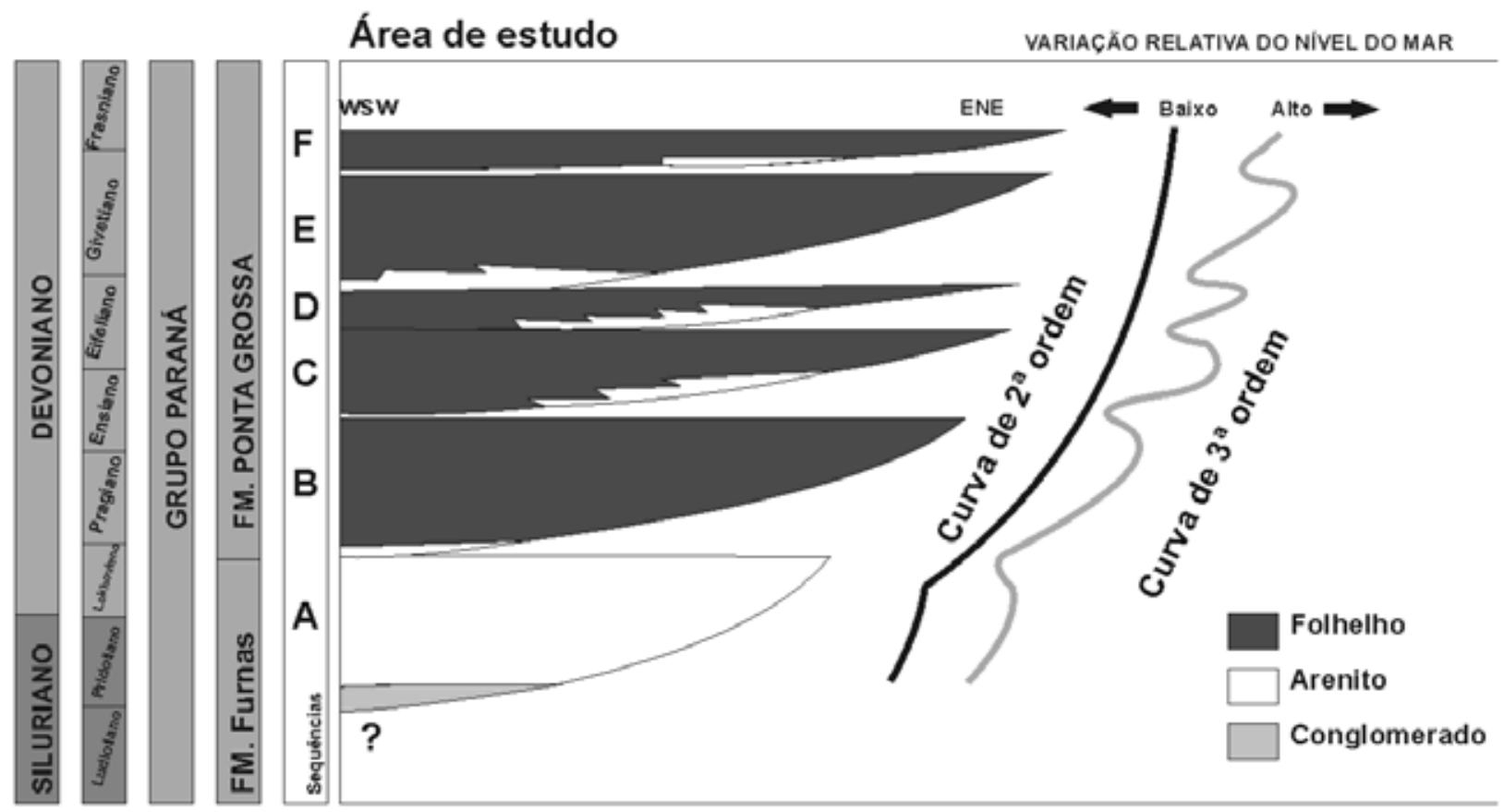

Figura 2 - Diagrama cronoestratigráfico para o intervalo Devoniano (modificado de Bergamaschi \& Pereira 2001). 
variedade de macrofósseis (trilobitas, braquiópodos, tentaculites etc.) e palinomorfos (acritarcas, quitinozoários etc.).

A Formação Ponta Grossa foi dividida litoestratigraficamente por Lange \& Petri (1967), onde, da base para o topo, foram nomeados os membros Jaguariaíva, Tibagi e São Domingos. Baseando-se em dados litológicos de afloramento e subsuperfície, Fúlfaro et al. (1980) reconheceram esta mesma subdivisão, nomeando os três membros como inferior, médio e superior. Em termos litológicos, o membro inferior (Jaguariaíva) e o superior (São Domingos) são, predominantemente, síltico-argilosos, enquanto que o membro intermediário (Tibagi) é constituído por arenitos de granulometria muito fina ou sílticos.

O Membro inferior (Jaguariaíva) é a unidade basal da Formação Ponta Grossa. Constitui-se de um pacote homogêneo de folhelhos sílticos de coloração cinza média/escura, frequentemente bioturbados. O mesmo apresenta uma idade praguiana-emsiana (Lange \& Petri 1967, Gaugris \& Grahn 2006). Os folhelhos são fossilíferos e portadores de formas malvinocáfricas, sobretudo braquiópodes e trilobitas.

O membro médio (Tibagi), no qual se encontram inseridos grande parte dos dados referentes a esse trabalho, sobrepõe o Membro Jaguariaíva. Posicionado no Eifeliano (Lange \& Petri 1967), os arenitos do Membro Tibagi constituem corpos com frequente padrão textural de granocrescência para o topo (Assine et al. 1998). São comumente finos a muito finos, sílticos, micáceos, apresentando estratificação plano-paralela, ondulada ou cruzada hummocky, quando não obliterada por bioturbação. Estes arenitos alimentam grande discussão acerca de sua formação. Assine (1996) propôs que estes arenitos seriam os reflexos do aumento do aporte sedimentar em relação ao espaço de acomodação, com nível do mar relativamente estacionário. Esta situação teria promovido a progradação deltaica em um trato de sistemas de mar alto. Para Bergamaschi \& Pereira (2001), os arenitos do Membro Tibagi constituiriam depósitos de shoreface que progadaram grandes distâncias, bacia adentro, em reposta às regressões forçadas. Recentemente, Cândido \& Rostirolla (2008) argumentaram sobre a possibilidade da parte basal do Membro Tibagi compreender um trato de sistemas de mar alto. Por outro lado, a parte superior deste membro, que congrega corpos arenosos de progradantes a agradantes corresponderia a um trato similar ao trato de sistemas de margem de plataforma. Para esses autores, o interior do Membro Tibagi encerraria, portanto, um limite de sequência originado por uma discordância do tipo II.

O Membro superior (São Domingos) é a unidade do topo, constituindo uma seção de folhelhos cinza de idade givetiana-frasniana (Lange \& Petri 1967, Grahn et al. 2002). A fauna é semelhante à do Membro Jaguariaíva, mas representada por um menor número de espécies, faltando formas tipicamente malvinocáfricas (Melo 1988).
MATERIAIS E MÉTODOS O testemunho de sondagem foi descrito em termos sedimentológicos, fotografado e amostrado, com o intuito de promover uma detalhada caracterização faciológica, identificar os processos envolvidos na sedimentação e definir o padrão do empilhamento estratigráfico. Após essa etapa as amostras foram impregnadas com resina epóxi azul para a identificação dos poros.

Foram confeccionadas seções delgadas objetivando caracterizar o processo diagenético dos arenitos. Esta caracterização forneceu dados para interpretar a história diagenética ocorrida e definir a influência da mesma na qualidade dos arenitos como reservatório de hidrocarbonetos.

Para a identificação dos carbonatos foi utilizada a técnica de tingimento. Para este procedimento foi utilizado uma solução de alizarina (10\%) e de ferricianeto em $\mathrm{HCl}$ diluído $(0,15 \%)$.

As amostras foram analisadas de maneira quantitativa através da contagem de 300 pontos em cada lâmina, com espaçamento de $0,3 \mathrm{~mm}$, onde se buscou reconhecer as modificações diagenéticas e a relação cronológica entre elas.

Para melhor caracterização diagenética dos arenitos estudados, foram empregadas análises de microscopia eletrônica de varredura (MEV). As amostras foram cobertas por uma fina camada metálica e foram examinadas usando-se uma aceleração de $20 \mathrm{kV}$ e uma corrente de difusão de 0,4 nA. Essa etapa foi realizada no Centro de Pesquisas e Desenvolvimento Leopoldo Américo Miguez de Mello (CENPES), Petrobras, bem como as análises de raios-X.

As análises de raios- $X$ obedeceram ao procedimento padrão utilizado pelo CENPES. As amostras, após serem pulverizadas em um suporte específico, foram prensadas de modo a terem suas partículas isentas de orientação. Para a análise dos argilominerais, as amostras foram imersas em água destilada e desagregadas por um aparelho de ultra-som por cerca de $3 \mathrm{~min}$. Em seguida, retirou-se por centrifugação $(700 \mathrm{rpm}$ por $6 \mathrm{~min}$ ) o material contido na fração granulométrica inferior a $2 \mu \mathrm{m}$ da suspensão estável obtida. Este material foi concentrado por centrifugação (10.000 rpm por 10 min). Da pasta resultante prepararam-se lâminas orientadas pelo método do esfregaço. Estas lâminas foram tratadas com etilenoglicol e aquecidas a $490^{\circ} \mathrm{C}$, a fim de se identificar os argilominerais. A velocidade de varredura do goniômetro foi de 6 graus por minuto. A interpretação dos difratogramas foi obtida por comparação com os padrões disponíveis na literatura científica. Estimaram-se os valores semiquantitativos dos argilominerais presentes a partir da medida da altura dos picos principais. As análises de raios- $X$ foram realizadas no CENPES e, também, no Laboratório de Análises Minerais e Materiais (LAMM-UFRRJ), onde se utilizou a mesma técnica empregada no CENPES.

Aspectos sedimentológicos e estratigráficos do furo estudado $O$ furo de sondagem descrito neste trabalho foi perfurado no município de Dom Aquino (MT) até a 
profundidade de $200,70 \mathrm{~m}$. O furo em questão engloba sedimentos do Devoniano Superior da Bacia do Paraná (Mendlowics Mauller 2008).

Esta região da Bacia do Paraná corresponde à sub-bacia de Alto Garças, caracterizada por sua porção basal arenosa e cada vez mais argilosa em direção ao topo, com arenitos subordinados (Freitas-Brazil, 2004). A divisão paleotectônica do Devoniano da Bacia do Paraná nas sub-bacias de Alto Garças e Apucarana foi originalmente proposta por Ramos (1970), com base em mapas de isópacas, elaborados para os sedimentos associados ao Devoniano Médio/Superior da bacia. A distribuição desses sedimentos, baseados em furos e afloramentos, permitiu a identificação de dois depocentros: um a norte e outro a sul, definindo assim, as sub-bacias de Alto Garças e de Apucarana, respectivamente.

Para o furo foram descritas seis fácies sedimentares, seguindo o trabalho de Oliveira \& Pereira (2008) (Fig. 3).

Os arenitos muito finos estão intercalados com siltito (Fácies A2), apresentando fraca laminação e bioturbação. Exibem estratificação cruzada hummocky e estrutura de carga.

O conjunto dos arenitos finos (Fácies A3) apresenta estrutura maciça, com bioturbação fraca a moderada, concreções calcíticas, filmes de lama, estratificação cruzada hummocky e siderita.

Ocorrem siltitos com intercalação de arenito fino (Fácies S2) na proporção 2:1 a 1:2, com intensa bioturbação, estratificação cruzada ondulante truncada, laminação ondulada, concreções, linsen e siderita, podendo apresentar laminação plano-paralela pouco definida.

Foram observados também siltitos de cor cinza a cinza escuro, com intercalação de arenito fino e lama (Fácies S3), bioturbado, com laminação plano-paralela pouco definida, estratificação ondulante truncada, laminação ondulante, climbing ripples, wave e linsen, concreção e siderita.

A Fácies F2 compreende folhelhos de coloração escura laminados, com intercalações de siltito e bioturbação, que apresentam laminação plano-paralela pouco definida.

Por fim, a Fácies F3 engloba folhelhos de coloração cinza escuro, com laminação plano-paralela e bioturbação. Estes são intercalados com arenitos finos e siltitos. Apresentam concreções calcíticas e siderita.

Segundo Mendlowics Mauller (2008), os depósitos estudados possuem uma idade givetiana-frasniana. No mesmo foi possível definir basicamente três ciclos deposicionais de $3^{\mathrm{a}}$ ordem, os quais foram correlacionados às sequências " $D$ ", "E" e "F" definidas por Bergamaschi \& Pereira (2001). As superfícies-chave das sequências $\mathrm{D}$ e $\mathrm{E}$ foram posicionadas com base em dados de Carbono Orgânico Total (COT), segundo Oliveira (2009) e Pereira et al. (2010). Já o limite entre as sequências "E" e "F" foi posicionado à profundidade de $61,0 \mathrm{~m}$, o qual coincide com o limite de sequência

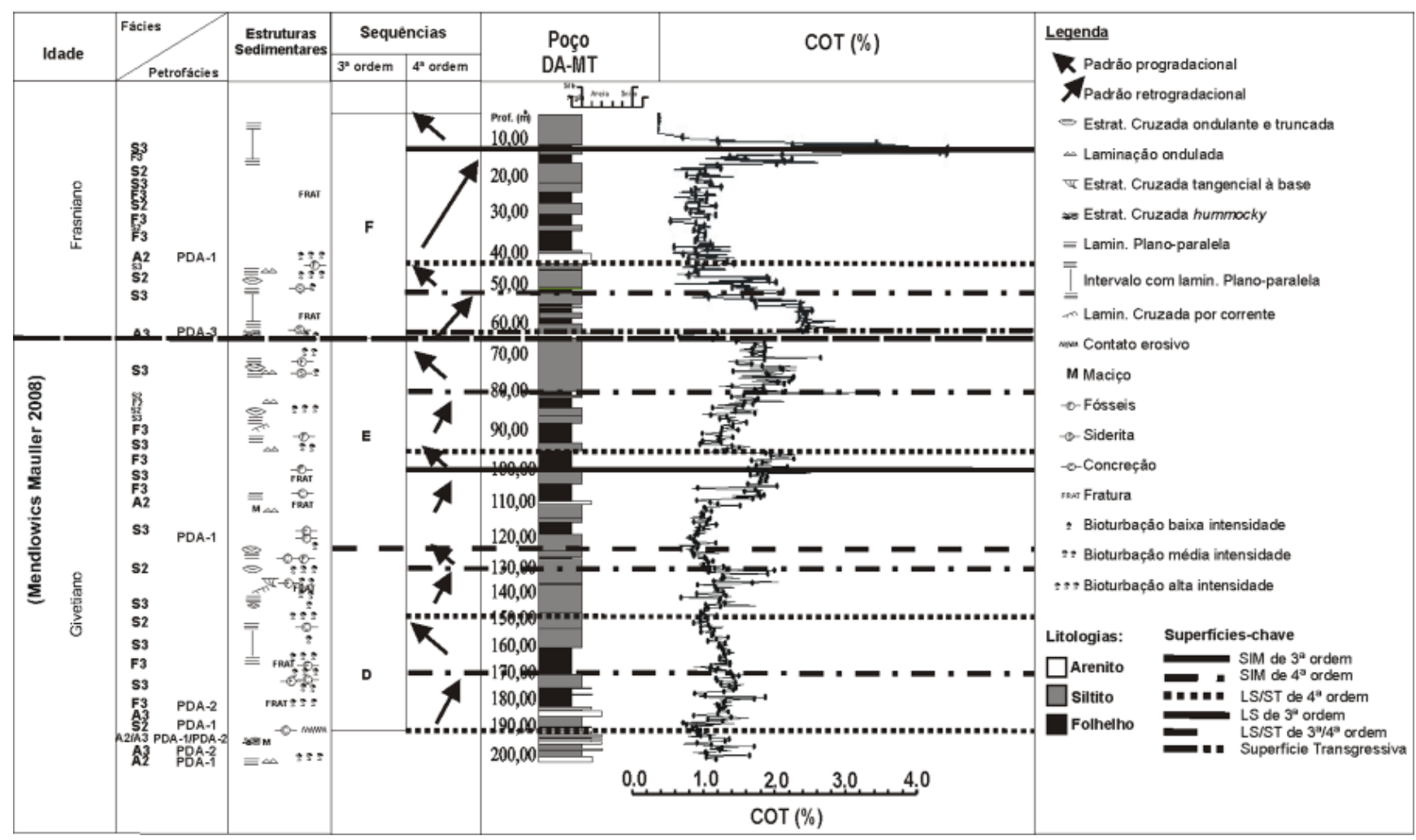

Figura 3 - Perfil sedimentológico para o furo estudado, destacando-se o posicionamento das amostras coletadas para a preparação de lâminas delgadas. 
(LS)/superfície transgressiva (ST), segundo dados bioestratigráficos de Mendlowics Mauller (2008). É possível também observar nas sequências ciclos de maiores frequências associados às sequências de $4^{\mathrm{a}}$ ordem, o que justifica a expressiva queda percentual do COT a partir de $40 \mathrm{~m}$. A superfície de inundação máxima (SIM) para o terceiro ciclo de deposição está posicionada no topo deste furo $(12 \mathrm{~m})$. A mesma é representada por folhelhos negros finamente laminados, intercalados a siltitos com até $4 \%$ de conteúdo de matéria orgânica (COT) (Pessôa de Souza 2006), depositados em ambiente marinho de costa-afora. De acordo com Pessôa de Souza (2006), a presença de elevados teores de COT no topo da seção marca claramente o ápice da tendência transgressiva observada ao longo de todo o intervalo Devoniano da Bacia do Paraná.

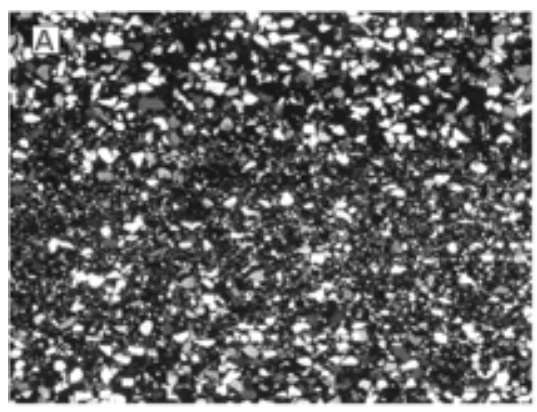

Lâmina: 39-DA. Profundidade: 195,35 m. (A) Arenito fino bimodal. Obetiva: $2,5 \mathrm{x}$. Nicóis cruzados.

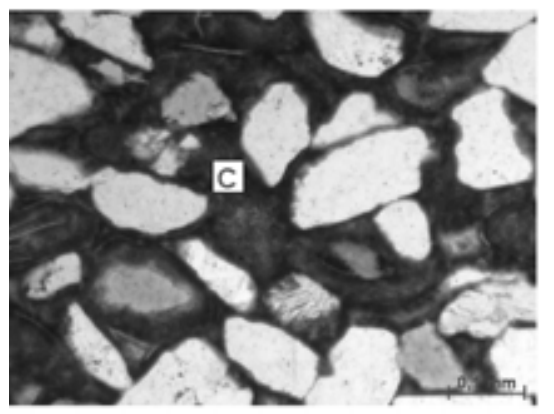

Lâmina: 38-DA. Profundidade: 193,55 m. (C) Franja de clorita delineando a porosidade. Objetiva de $20 \mathrm{x}$. Nicóis paralelos.

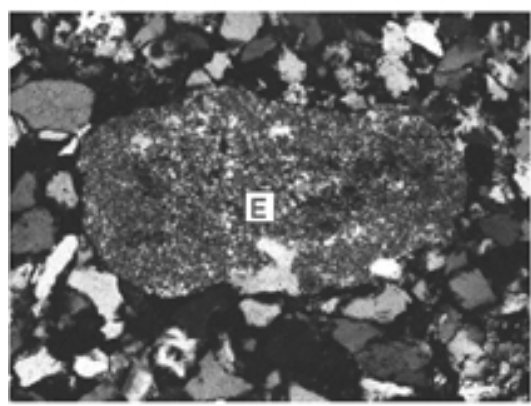

Lamina: 25-DA. Profundidade: $181,50 \mathrm{~m}$ (E) Litoclasto.

Objetiva: 10x. Nicóis cruzados.
RESULTADOS E DISCUSSÕES De maneira geral, os arenitos da Formação Ponta Grossa apresentam granulometria variando de fina a muito fina. $\mathrm{O}$ arredondamento dos grãos é em geral subangular a subarredondado (Folk 1980) (Fig. 4). No entanto, devido ao processo diagenético de crescimento sintaxial de quartzo, a determinação desse arredondamento foi dificultada. Os arenitos são moderadamente bem selecionados. Observou-se, intercalados aos arenitos, um volume considerável de níveis argilosos bioturbados.

Os grãos de quartzo possuem extinção reta a fracamente ondulante, sendo estes principalmente monocristalinos. O baixo teor de quartzo policristalino nos arenitos estudados é provavelmente devido à sua granulometria fina. Apresentam inclusões e cobertura parcial ou total de crescimento secundário de quartzo.

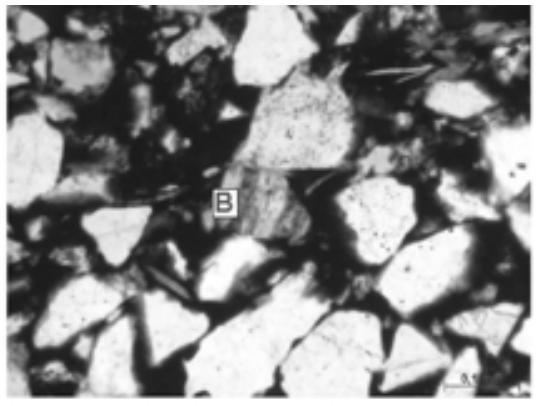

Lâmina: 39-DA. Profundidade: $195,35 \mathrm{~m}$.

(B) Dissolução de grảo de plagioclásio. Obetiva: 20x. Nicóis cruzados.

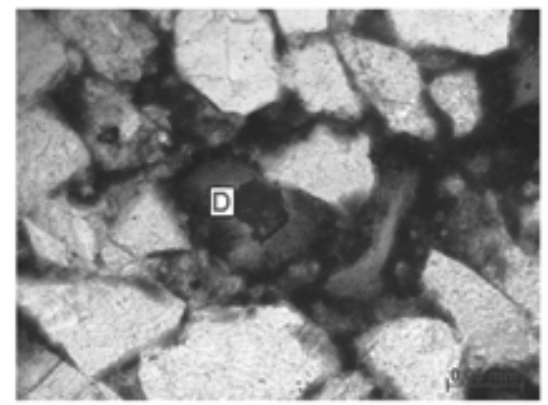

Lâmina: 27-DA. Profundidade: 188,55 m (D) Óxido de titânio precipitado em poro móldico Objetiva de 10x. Nicóis paralelos.

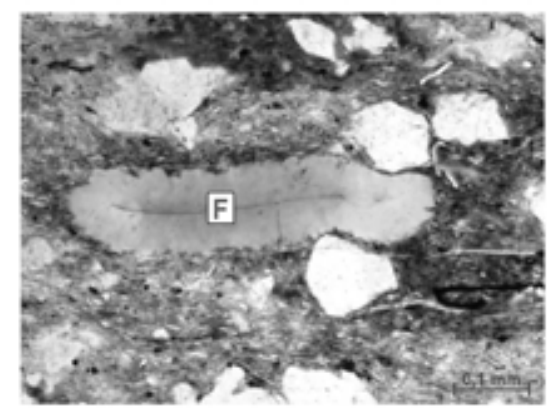

Lâmina: 38-DA. Profundidade: 193,55 m. (F) Bioclasto

Objetiva: $20 \mathrm{x}$. Nicóis paralelos

Figura 4 - Aspectos texturais e composicionais dos arenitos estudados. 
A porcentagem média de quartzo é de $52,2 \%$. Os feldspatos estão largamente dissolvidos, sendo substituídos por caolinita. A média de feldspato é de 1,1\%.

Dentre os minerais acessórios, se destaca a muscovita com média de 2,2\%. Estas são mais frequentes nos arenitos de granulometria mais fina. Possuem o hábito tabular e mostram forte ilitização e caolinização durante o processo diagenético. Por serem minerais flexíveis, as muscovitas sofrem os efeitos da compactação mecânica. Ocorrem também os minerais pesados como zircão, rutilo e turmalina $(0,1 \%)$. Litoclastos foram observados com alguma frequência (média de $0,5 \%$ ).

Os bioclastos representam $0,3 \%$ do volume total das amostras. São compostos por algas Tasmanites (cistos de algas prasinóficas planctônicas) (Freitas-Brazil 2004) que predominam principalmente nos arenitos micáceos. Estas ocorrem sob diversas formas e por vezes seu interior encontra-se substituído por pirita framboidal.

Segundo o diagrama de Folk (1980), um diagrama ternário tipo QFL (quartzo, feldspato e líticos), os arenitos do intervalo Givetiano-Frasniano foram, quase que na sua totalidade, classificados como quartzoarenitos e, secundariamente, como sublitoarenitos (Fig. 5). Obteve-se essa classificação recalculando-se as porcentagens de quartzo total, feldspato total e fragmentos líticos totais. Nos arenitos de Dom Aquino percebe-se certa heterogeneidade da composição detrítica. Isto estaria relacionado ao fato destas rochas estarem posicionadas em condições mais proximais à área fonte, como evidenciado pelos percentuais de litoclastos em sua composição.

\section{Petrofácies identificadas no furo estudado e evolu-} ção diagenética De acordo com os resultados obtidos com a análise quantitativa dos dados petrográficos foi

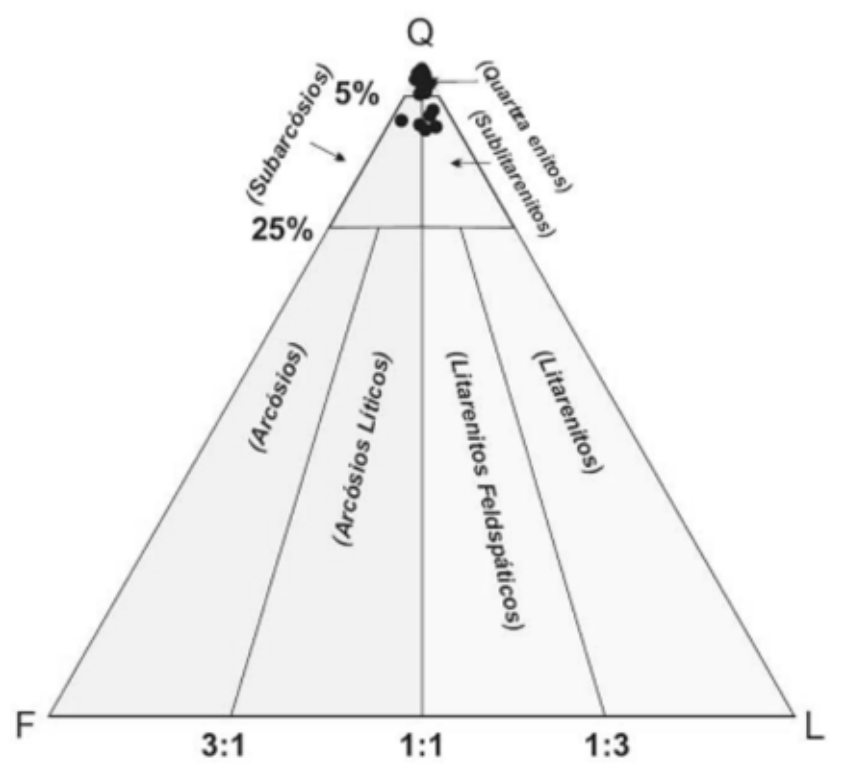

Figura 5 - Classificação dos arenitos estudados na região de Dom Aquino (MT) (modificado de Folk 1980). possível individualizar três petrofácies para o furo estudado. Utilizou-se como critério diferenciador para estas petrofácies a porcentagem dos minerais detríticos e dos constituintes diagenéticos, bem como as características texturais dos arenitos.

PETROFÁCIES PDA-1 As amostras desta petrofácies estão associadas à fácies A2. Compreende arenitos muito finos, de coloração cinza, com granulação variando de areia muito fina a fina. Os mesmos mostram grãos subangulares a subarredondados, moderadamente bem selecionados, laminação incipiente e frequentemente bioturbados. Apresenta quartzo monocristalino, k-feldspato (microclínio e ortoclásio), plagioclásio, muscovita, bioclasto (algas Tasmanites), quartzo microcristalino, turmalina e zircão. Ocorrem argilas infiltradas associadas à bioturbação, bem como caolinita, siderita, óxido de titânio, pirita (associada à bioturbação), bertierina em forma de cutícula e como cimento, quartzo, calcita pobre em $\mathrm{Fe} 2+$ e anquerita.

PETROFACIES PDA-2 Essa petrofácies associa-se à fácies sedimentar A3. Trata-se de arenitos finos, de cor cinza, com granulação variando de fina a média, com grãos subangulares a subarredondados, moderadamente bem selecionados, laminação incipiente, bioturbado, composto principalmente por quartzo mono (principalmente) e policristalino, k-feldspato (microclínio e ortoclásio), plagioclásio, muscovita, bioclasto (algas Tasmanites), quartzo microcristalino, e zircão. Como minerais diagenéticos ocorrem: óxido de ferro cimentando a rocha, óxido de titânio, dolomita (livre $\mathrm{Fe}+2$ ), siderita em nódulos e como cimento, pirita (associada à bioturbação) e clorita. Nesta petrofácies acorrem, de forma esporádica, ooides de bertierina oxidados e dissolvidos.

PETROFÁCIES PDA-3 Esta petrofácies associa-se também à fácies A3. A mesma foi individualizada, principalmente, por apresentar mais de $60 \%$ de ooides de bertierina e de óxido de ferro (ironstone) (Fig. 6). Como minerais diagenéticos ocorrem: Siderita associada à bioturbação e como cimento (extinção ondulante), hematita, dolomita (livre de $\mathrm{Fe} 2+$ ) e calcita (pobre e livre de $\mathrm{Fe} 2+$ ). A granulometria varia de areia fina a média, com grãos arredondados a bem arredondados, muito bem selecionados, laminação incipiente, e alguma bioturbação. A porosidade é baixa, sendo a mesma móldica e alargada.

$\mathrm{Na}$ região estudada, as alterações diagenéticas observadas ocorreram de maneira similar àquelas observadas por Freitas-Brazil (2004). Essa autora estudou três furos localizados em Mato Grosso e Mato Grosso do Sul. Assim, resumidamente, a história diagenética para os arenitos desta região norte da Bacia do Paraná compreende os eventos eodiagenéticos relacionados: (i) à precipitação de bertierina na forma de cutículas e na forma de ooides na petrofácies PDA-3. Há ainda a precipitação de siderita na forma de nódulos e como cimento na petrofácies PDA-2 e PDA-3; e (ii) à fase eodiagenética secundária que é marcada pela precipitação de pirita e dolomita (petrofácies PDA-1).

As fases mesodiagenéticas, que ocorreram pós-compactação química, foram: (i) raro crescimento 


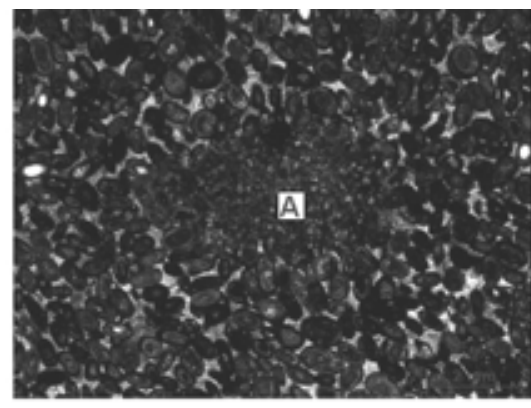

Lâmina: 07-DA. Profundidade: $60,90 \mathrm{~m}$ (A) Bioturbaçito.

Objetiva de 2,5x. Nicóis paralelos.

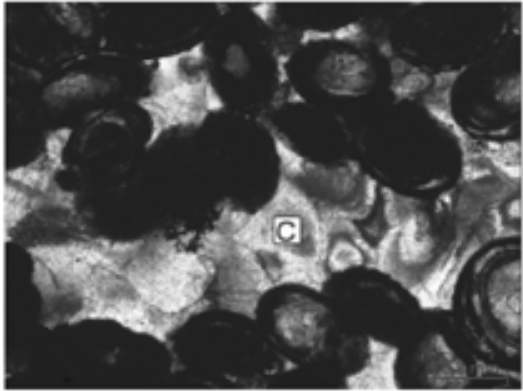

Lâmina 10-DA. Profundidade: $61,17 \mathrm{~m}$. (C) Cimentatçấo por siderita Observe a extinção radial característica. Objetiva de 10x. Nicóis cruzados.

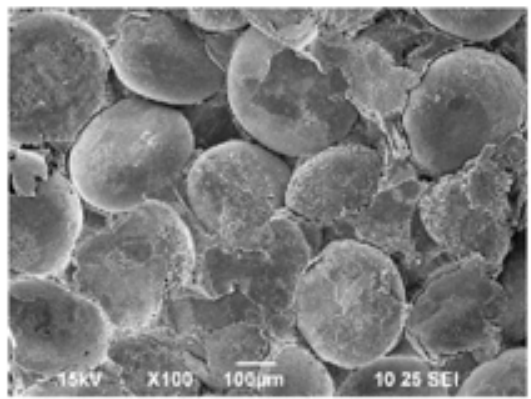

Imagem de MEV. Aspecto geral da 15 mina 09.DA. Petrofácies PDA-3

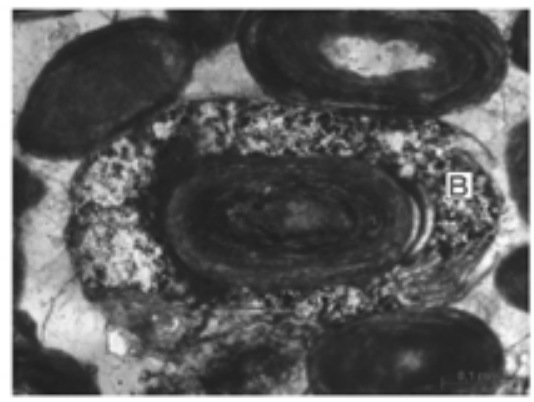

Lâmina: 09-DA. Profundidade: $61,05 \mathrm{~m}$ (B) Calcita pobre em $\mathrm{Fe} 2+$ determinada por colorimetria (violeta) Objetiva de 20x. Nicóis paralelos.

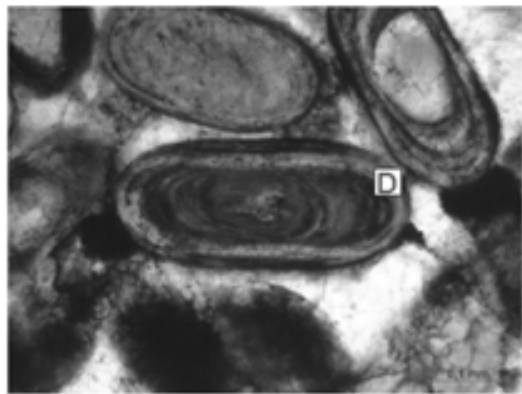

Profundidade: $61,17 \mathrm{~m}$. Lâmina 10-DA. (D) Ooides de bertierina sendo substitido por siderita. Objetiva de 20x. Nicóis paralelos

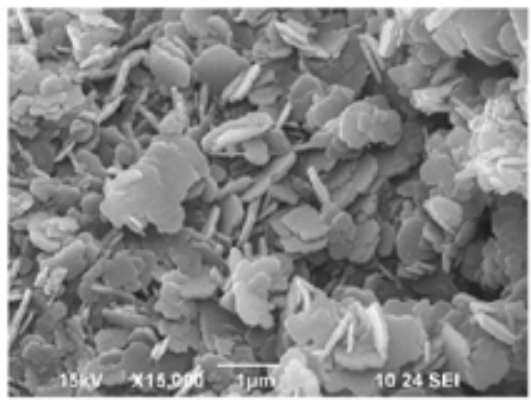

Imagem de MEV.

Franja de clorta formada por pseudoplaquetas hexagonais. Petroficies PDA-3

Figura 6 - Diferentes aspectos petrográficos dos ooides de bertierina e de óxido de ferro.

secundário de quartzo (petrofácies PDA-1); (ii) evolução da bertierina para chamosita; e (iii) cimentação por calcita e anquerita (principalmente na petrofácies PDA3). Ocorre também a precipitação de óxido de titânio. Por fim, as fases telodiagenéticas foram: (i) geração de porosidade secundária; e (ii) precipitação de caolinita.

Caracterização dos ironstones $\mathrm{O}$ argilomineral bertierina foi descrito pela primeira vez por Orcel et al. (1949 apud Velde 2003) associado à ooides de óxidos de ferro. É um mineral característico dos ambientes marinho rasos (Odin 1988), formado em condições diagenéticas de temperatura superior a $70^{\circ} \mathrm{C}$ (Velde 2003). Possui pouco ou nenhum íon de $\mathrm{Fe}^{+3}$, sendo os mesmos argilominerais aluminosos ricos $\mathrm{em} \mathrm{Fe}^{+2}$ $\left(\left[\mathrm{Fe}^{2+}{ }_{2} \mathrm{Al}(\mathrm{SiAl})_{2} \mathrm{O}_{5}(\mathrm{OH})_{4}\right]\right)$, pertencentes à série da serpentina-caolinita (Deer et al. 1996).

Esse mineral possui grande importância na diagênese da Formação Ponta Grossa, como visto por Freitas-Brazil (2004), sobretudo no Devoniano Superior. O mesmo foi observado com frequência no furo estudado, o qual está posicionado estratigraficamente no limite Givetiano/Frasniano (Mendlowics Mauller 2008).

A bertierina ocorre nos níveis estudados como cutículas, cimentando as rochas e, principalmente, na forma de ooides (Fig. 6). Considerou-se, pela análise paragenética, que as bertierinas se formaram antes da siderita e do crescimento secundário de quartzo. 
A singularidade dos fatores responsáveis pela ocorrência de bertierina e de glauconita pode ajudar em importantes inferências ambientais. De acordo com o trabalho de Odin (1988), a bertierina está presente em ambientes próximos a deltas e estuários, enquanto que a glauconita é frequentemente encontrada em ambientes mais profundos. A principal diferença na evolução química destes dois tipos de argilominerais reside na mudança de ferro férrico para ferroso na bertierina. A redução de ferro nos deltas e em sedimentos ricos em matéria orgânica produziria a bertierina, enquanto que a formação das glauconitas está relacionada ao ferro, essencialmente férrico, contido em pellets de microorganismos e com a presença de potássio, em ambientes sob baixa taxa de sedimentação e com ausência de um forte agente redutor.

E importante notar que os primeiros estudos sobre este mineral, o indicavam como pertencente ao grupo das cloritas. Entretanto, cloritas e bertierinas apresentam leves diferenças composicionais em relação à quantidade de íons entre seus octaedros (de 3,0 a 2,5 nas cloritas e de 3,0 a 2,75 nas bertierinas; Velde 2003). Dessa maneira, por razões cristalográficas, considera-se a bertierina pertencente a grupo da serpentina-caulinita. Portanto, sua determinação nas amostras estudadas foi difícil de ser realizada, mesmo com auxílio da difratometria de raios- $X$, devido à grande similaridade de seus picos em 7,2 Á (Velde 2003), com os picos da clorita (chamosita), em $14 \AA$ e, consequentemente, em $7 \AA$ (Fig. 7). Acredita-se que a chamosita presente nesses arenitos seja produto de uma provável transformação isoquímica mesodiagenética da bertierina (Hornibrook \& Longstaffe 1996; Morad et al. 2000; Velde 2003), em temperaturas em torno de $120-160^{\circ} \mathrm{C}$ (Curtis 1985).

A origem de ooides de ferro no registro sedimentar tem sido assunto de muitos debates nas últimas décadas. Vários modelos foram propostos tentando explicar sua gênese. No entanto, todos esses trabalhos padecem de respostas específicas para o entendimento de algumas questões, tais como: seu enriquecimento em ferro, sua mineralogia e, principalmente, sua textura ooidal.

Os modelos incluem propostas relacionadas à substituição de ooides de calcário (Kimberley 1974), à formação por acresção mecânica (Kearsley 1989) e, associados, à erosão de solos lateríticos (Siehl \& Thein 1989). Para Sturesson (1995) e Sturesson et al. (2000) tanto a fonte de ferro, quanto as condições necessárias para a formação dos oólitos seriam associadas às atividades vulcânicas, de modo que as cinzas vulcânicas e fluidos hidrotermais enriqueceriam a água do mar em $\mathrm{Fe}, \mathrm{Al}$ e Si.

Os trabalhos de Young (1989), Taylor et al. (2002) e Collin et al. (2005) advogam a ideia da formação desses ooides abaixo da superfície deposicional. Young (1989) associa a formação dos ironstones ordovicianos do oeste europeu a ciclos transgressivos de primeira e segunda ordem, nas quais haveria o enriquecimento de ferro durante os períodos de não deposição, com a formação de hardgrounds sideríticos. No período de tempo em que essa fina camada se forma, haveria degradação da matéria orgânica nas zonas óxicas e subóxicas, permitindo a formação autigênica de silicatos de ferro, inibindo a subsequente redução de sulfato.

Segundo Hallam \& Bradshaw (1979 apud Van Houten 1982), ironstones são depósitos que se desenvolvem, ou no fim de uma regressão regional, ou no início de uma transgressão (Gygi 1981, Kimberley 1979 apud Van Houten 1982). Donaldson et al. (1999) associaram a deposição dos irosntones Eo-Coniacianos do oeste da Bacia do Canadá às superfícies transgressivas em condições de baixas taxas de sedimentação. Esses mesmos autores concluíram ainda que esses depósitos não se relacionariam a limites de sequências ou a superfícies de inundação máxima.

Taylor et al. (2002) e Collin et al. (2005) postulam que a formação desses ironstones estaria relacionada a estágios de deposição dos argilominerais e óxidos de ferro, alternados com períodos de retrabalhamento por correntes de tempestade (Fig. 8).

Freitas-Brazil (2004) aventou ainda a possibilidade de esses ooides serem formados na superfície de deposição, associados à ação biogênica do icnofóssil Spyrophiton.

Descarta-se neste trabalho uma origem por associação vulcânica como proposto por Sturesson (1995) e Sturesson et al. (2000), visto que não há registro de vulcanismo para o Devoniano da Bacia do Paraná. Assim, neste estudo, acredita-se que os ooides de bertierina do noroeste da Bacia do Paraná teriam se formado abaixo da superfície transgressiva, estando de acordo com os modelos de Young (1989), Taylor et al. (2002) e Collin et al. (2005). Na fase final da diagênese (telodiagênese), haveria a oxidação desses depósitos e a subsequente substituição da bertierina por goetita e hematita (Figs. 6 e 9). Um dado que corrobora com esta hipótese está disposto na tabela 1 , onde é possível observar maiores percentuais de alumínio no centro do ooides (bertierina/clorita), e maiores concentrações de ferro na borda do ooides (goetita) (Tab. 2).

\section{Os ironstones no contexto estratigráfico regional} De acordo com publicações recentes acerca do posicionamento estratigráfico de determinados minerais eodiagenéticos (Amorossi 1997, Morad et al. 2000, Ketzer 2002, Ketzer et al. 2003, Worden \& Morad 2003), buscou-se desenvolver neste estudo uma comparação entre o arcabouço estratigráfico de $3^{\mathrm{a}}$ e $4^{\mathrm{a}}$ ordem proposto para o furo analisado com a distribuição desses minerais.

De acordo com Morad et al. (2000), a distribuição espacial e temporal das alterações diagenéticas nas sequências siliciclásticas é fortemente controlada por um complexo arranjo de parâmetros inter-relacionados que conduzem as alterações durante a eodiagênse, mesodiagênese e telodiagênese. Estes parâmetros incluem: ambiente tectônico, história térmica e de soterramento da bacia, evolução geoquímica, origem da água de poro (ou água de formação), ambiente deposicional e fácies, condições climáticas, propriedade físicas e químicas 
dos grãos do arcabouço, quantidade e reatividade da matéria orgânica, tempo de entrada e grau de saturação dos hidrocarbonetos na rocha e mudanças relativas do nível do mar.

As mudanças relativas do nível do mar e o aporte sedimentar são os principais fatores que controlam os eventos regressivos e transgressivos de uma bacia sedimentar. Estes eventos controlam a composição detrítica e o tempo de residência dos sedimentos, bem como a posição e a dinâmica da química da água de poro, sendo a última de fundamental importância no grau de mistura entre a água marinha e continental (Morad et al. 2000,
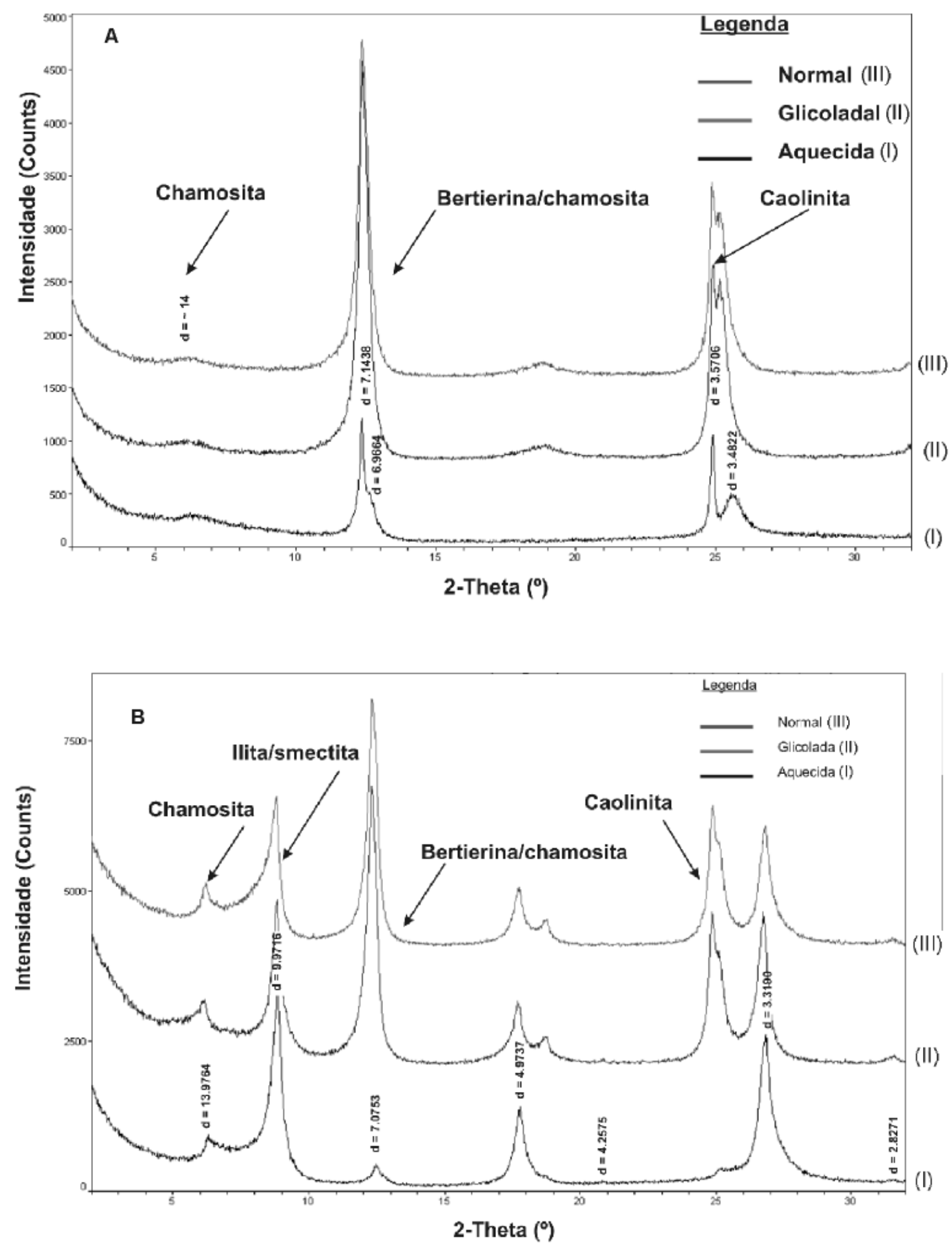

Figura 7 - (A) Análise de difratometria de raios-X da amostra 09-DA. Foi identificada a bertierina com base nos picos de 7,14 Á, valor esse bem próximo ao proposto por Velde (2003); (B) Análise de difratometria de raios- $X$ da amostra 16-DA. É identificada a ilita interestratificada com esmectita com picos de $\sim 10 \dot{A}, \sim 5 \dot{A}$ e $3,3 \dot{A}$. Observe que não há mudança no comportamento da ilita na presença do etlinoglicol e do calor $\left(550^{\circ} \mathrm{C}\right)$. 
Ketzer et al. 2003). Desta maneira, tais eventos, somados à ação climática e à composição detrítica de uma determinada fácies deposicional, terão forte influência nas reações eodiagenéticas das rochas siliciclásticas (Morad et al. 2000, Ketzer et al. 2003, Worden \& Morad 2003).

Durante o processo diagenético, as variações do nível do mar podem influenciar nas modificações de certos minerais, o que gera uma ligação entre os aspectos diagenéticos e as superfícies-chave das sequências deposicionais. Contudo, sob soterramento profundo, muitos intervalos podem ser fortemente substituídos por carbonato. Isto pode dificultar a correlação da eodiagênese com o arcabouço estratigráfico definido.

No entanto, como não foram observados elementos que caracterizem uma diagênese profunda para o estudo aqui realizado, foi possível estabelecer algumas correlações entre o arcabouço estratigráfico e os eventos eodiagenéticos. As principais correlações estão relacionadas à distribuição dos minerais eodiagenéticos, os quais aumentam suas concentrações em direção às superfícies de inundação. Portanto, o contexto do Devoniano da Bacia do Paraná que é marcado por ambientes pouco profundos, caracterizados por tratos trangressivos, que propiciam a decomposição da matéria orgânica e, concomitantemente, reações de oxirredução de óxidos metálicos, principalmente de ferro, favorece a correlação entre o arcabouço estratigráfico e a ocorrência de minerais eodiagenéticos. Estes ambientes teriam gerado uma assembleia mineral típica, formada especialmente por siderita, pirita, glauconita e, especialmente, nos arenitos estudados, por bertierina.

$\mathrm{Na}$ base do furo de sondagem analisado, a profundidade de $193 \mathrm{~m}$ é marcada por uma grande concentração de bertierina/chamosita e, principalmente, siderita. Ocorre também pico de pirita framboidal. Neste mesmo ponto, observa-se um notável decréscimo no volume de quartzo e um considerável volume de macroporosidade, o qual atinge o percentual de $12 \%$. Na profundidade de $60 \mathrm{~m}$ ocorre a presença dos ooides de bertierina (ironstones). Neste nível também ocorre siderita em elevados percentuais, sendo que a macroporosidade é baixa.

Como anteriormente discutido, a bertierina se forma em condições de soterramento pouco profundo, onde há uma progressiva diminuição da quantidade de oxigênio dissolvido na água de poro, na zona de redução de nitrato (Taylor \& Curtis 1995). Na região

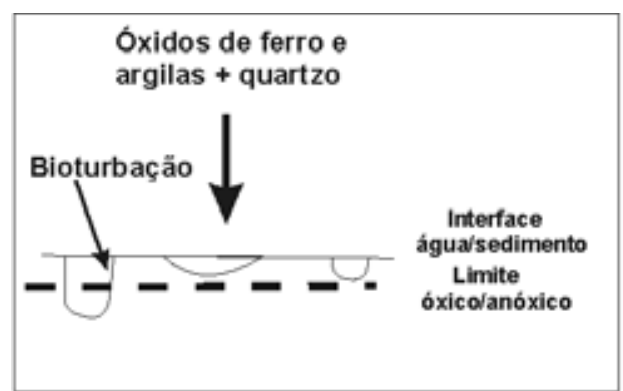

A. Deposição de argilas, gräos finos de quartzo e óxidos de ferro

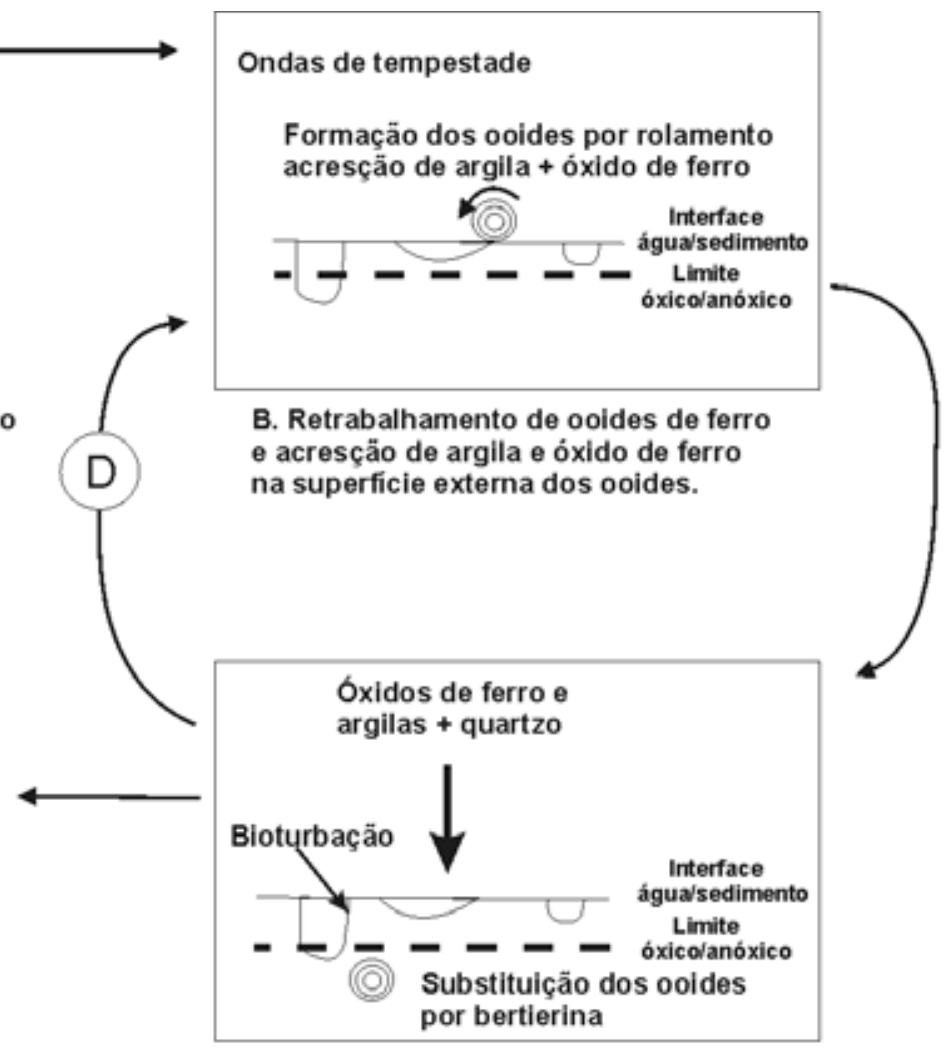

C. Substituição de óxido de ferro e cuticulas de argila nos ooides por bertierina durante a diagênese subóxica. (D) Repetiçăo dos processos ocorridos na fase B e C resulta em ooide com cutículas concêntricas.

Figura 8 - Hipótese para os estágios de formação e diagênese dos ooides de óxido de ferro, segundo Taylor et al. (2002). O modelo tem por referência os ironstones de Castlegate (Utah, Estados Unidos) e da Formação Peace River (Alberta, Canadá). Modificado de Taylor et al. (2002). 

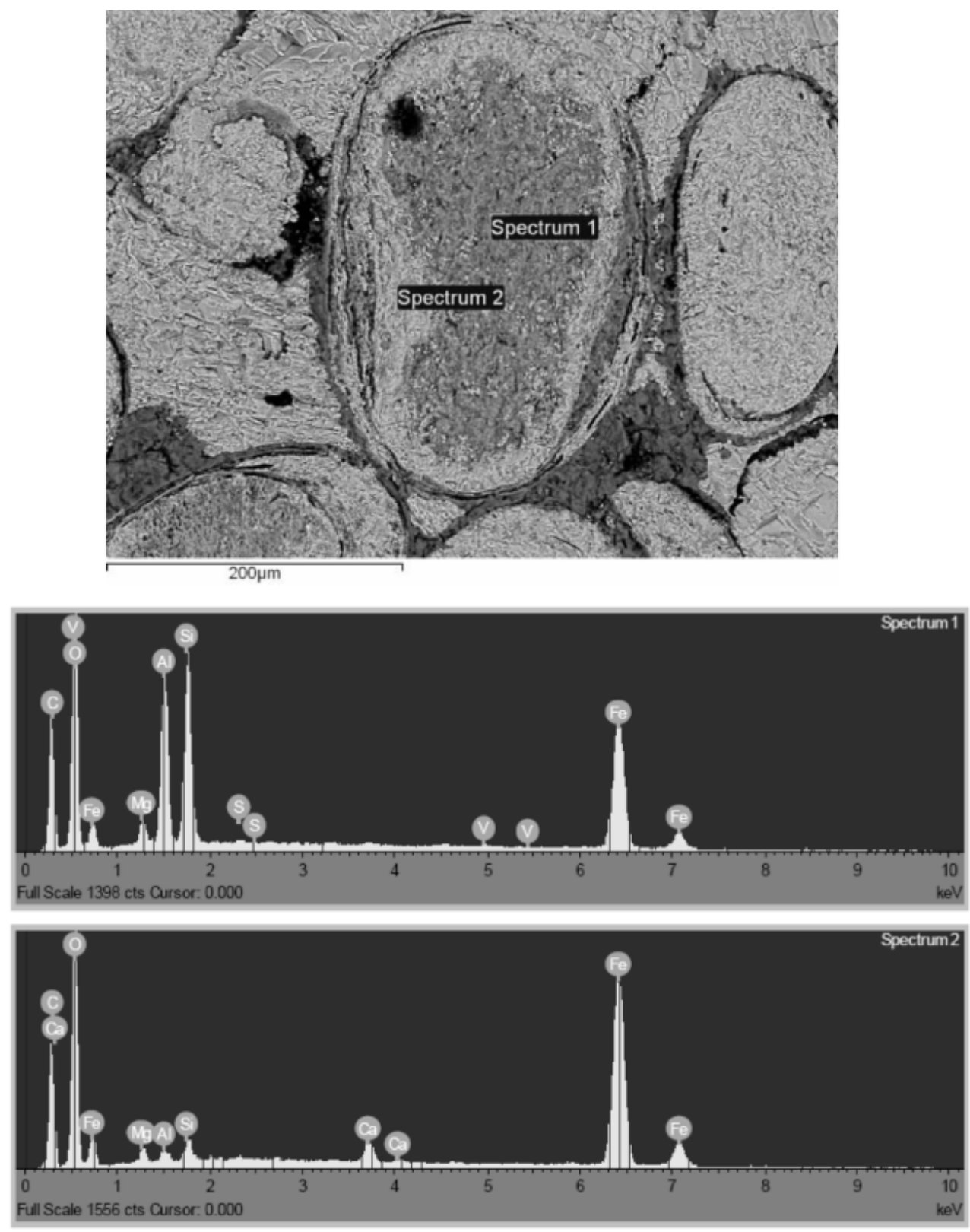

Figura 9 - Imagem de MEV/EDS de ooides de bertierina. Os altos teores de alumínio e ferro no spectrum 1 podem estar indicando um interestratificado de bertierina e clorita. No spectrum 2 é possivel notar as bordas do ooides sendo oxidadas (goetita), o que reduz a concentração de aluminio e aumenta a de ferro. Lâmina 09-DA.

Tabela 1 - Percentual composicional relativo em peso dos elementos do spectrum 1 (exceto $\mathrm{C}$ e $\mathrm{O}$ ).

\begin{tabular}{lcccc}
\hline \multicolumn{5}{c}{ Spectrum 1 } \\
\hline Elemento & $\begin{array}{c}\text { Peso } \\
\text { (\%) }\end{array}$ & $\begin{array}{c}\text { Peso } \\
\text { Atômico (\%) }\end{array}$ & $\begin{array}{c}\text { Concentração } \\
(\%)\end{array}$ & Fórmula \\
\hline $\mathrm{Mg} \mathrm{K}$ & 2,19 & 2,23 & 3,64 & $\mathrm{MgO}$ \\
\hline $\mathrm{Al} \mathrm{K}$ & 11,67 & 10,70 & 22,05 & $\mathrm{Al}_{2} \mathrm{O}_{3}$ \\
\hline $\mathrm{Si} \mathrm{K}$ & 14,68 & 12,93 & 31,40 & $\mathrm{SiO}_{2}$ \\
\hline $\mathrm{S} \mathrm{K}$ & 0,31 & 0,24 & 0,78 & $\mathrm{SO}_{3}$ \\
\hline Fe K & 32,75 & 14,51 & 42,13 & $\mathrm{FeO}$ \\
\hline $\mathrm{O}$ & 38,40 & 59,38 & & \\
\hline Totais & 100 & 100 & 100 & \\
\hline
\end{tabular}

Tabela 2 - Percentual composicional relativo em peso dos elementos do spectrum 2 (exceto $\mathrm{C}$ e $\mathrm{O}$ ).

\begin{tabular}{lcccc}
\hline \multicolumn{5}{c}{ Spectrum 2 } \\
\hline Elemento & $\begin{array}{c}\text { Peso } \\
(\%)\end{array}$ & $\begin{array}{c}\text { Peso } \\
\text { Atômico (\%) }\end{array}$ & $\begin{array}{c}\text { Concentração } \\
(\%)\end{array}$ & Fórmula \\
\hline $\mathrm{Mg} \mathrm{K}$ & 2,46 & 3,32 & 4,08 & $\mathrm{MgO}$ \\
\hline $\mathrm{Al} \mathrm{K}$ & 1,27 & 1,54 & 2,39 & $\mathrm{Al}_{2} \mathrm{O}_{3}$ \\
\hline $\mathrm{Si} \mathrm{K}$ & 2,09 & 2,44 & 4,48 & $\mathrm{SiO}_{2}$ \\
\hline $\mathrm{Ca} \mathrm{K}$ & 2,48 & 2,03 & 3,47 & $\mathrm{CaO}$ \\
\hline $\mathrm{Fe} \mathrm{K}$ & 66,52 & 39,06 & 85,58 & $\mathrm{FeO}$ \\
\hline $\mathrm{O}$ & 25,18 & 51,61 & & \\
\hline Totais & 100 & 100 & 100 & \\
\hline
\end{tabular}


estudada, a mesma está estritamente associada à chamosita. A bertierina evolui para chamosita em condições de alta temperatura.

Como discutido por diversos autores (Morad et al. 2000, Ketzer 2002, Ketzer et al. 2003, Worden \& Morad 2003), a abundância de cutícula de bertierina/ chamosita é maior no Trato de Sistema Transgressivo (TST), em comparação com o Trato de Sistema de Mar Alto (TSMA). Neste último, em função da maior progradação das fácies e oxigenação do meio, as condições ambientais seriam pouco favoráveis para a formação deste mineral.

A bertierina foi observada na área estudada também sob a forma de ooides. A formação desta fácies rica em ferro, nesta região, está posicionada, especialmente, abaixo da Superfície Transgressiva (ST), associada às sequências de quarta ordem identificadas no furo, com base nos dados sedimentológicos e de raios-gama e de carbono orgânico total (COT). A base destas sequências é caracterizada por depósitos arenosos, os quais seriam reflexos de uma deposição ocorrida num contexto de regressão forçada (Bergamaschi \& Pereira 2001). Este conceito poderia explicar a formação e a concentração de ironstones de bertierina numa escala de $4^{\mathrm{a}}$ ordem.

De acordo com o modelo proposto para a formação dos ironstones de bertierina (Fig. 10) haveria, no primeiro estágio associado a um ambiente marinho raso, a deposição de argilas (bertierina) e óxidos de ferro, alternada com períodos de correntes de tempestade, as quais seriam responsáveis pela textura oolítica destes depósitos. Ainda neste estágio ocorreria cimentação por siderita. A formação de siderita ocorreria durante a eodiagênese subóxica. Assim, com a contínua redução de ferro, tanto abiótica quanto por ação de bactérias, a concentração de bicarbonato $\left(\mathrm{HCO}_{3}^{-}\right)$na água aumenta e a siderita $\left(\mathrm{FeCO}_{3}\right)$ torna-se o mineral de ferro mais estável (Taylor \& Curtis 1995). Esse argumento para estabilidade da siderita indica que este mineral, no noroeste da Bacia do Paraná, como também a bertierina, teria se formado após o soterramento inicial dos sedimentos, em tempos de baixa concentração de sulfetos na água de poro. A siderita nesta região ocorre, entre outras formas, substituindo a bertierina. Assim, de acordo com Taylor \& Curtis (1995), acredita-se que com a extensa formação de bertierina, no Devoniano Médio-Superior, pela contínua redução de ferro, houve grande concentração de bicarbonato na água de poro. Isto teria gerado condições propícias para precipitação de siderita.

No segundo estágio, adotando o modelo de regressões forçadas (Bergamaschi \& Pereira 2001), há a exposição da plataforma e, consequente retrabalhamento da assembleia mineral formada no primeiro estágio. $\mathrm{Na}$ base do furo estudado, há um espesso pacote arenoso, caracterizado por arenitos muito finos a finos, com ooides de bertierina dissolvidos (petrofácies PDA-2). $\mathrm{O}$ mesmo seria resultado dos processos deposicionais ativos neste estágio de exposição da plataforma, durante o qual houve dissolução do arcabouço e oxidação de minerais ferrosos (goetita substituindo bertierina).
No terceiro estágio há nova transgressão e o desenvolvimento de uma superfície transgressiva de $4^{\mathrm{a}}$ ordem. Abaixo dessa superfície ocorreria a concentração dos ooides (petrofácies PDA-3), os quais se apresentam imbricados.

Freitas-Brazil (2004) também identificou ironstones em posição estratigráfica similar (limite Givetiano/Frasniano) aos observados no furo analisado neste trabalho. Os ironstones descritos pela autora distam cerca de $100 \mathrm{~km}$ do furo aqui discutido. Dessa maneira, como a Bacia do Paraná apresenta uma fisiografia em rampa, modelos de regressões forçadas, que podem gerar imensas áreas de exposição, favorecendo a formação de limites de sequências de enorme extensão regional, poderiam explicar a distribuição estratigráfica dos ironstones, os quais seriam concentrados na transgressão subsequente a queda relativa do nível do mar.

CONCLUSÕES O estudo aqui desenvolvido mostrou que, sendo o ambiente deposicional o principal agente direcionador das modificações eodiagenéticas (Worden \& Morad 2003), é possível inferir que as mudanças relativas do nível do mar, juntamente com uma série de parâmetros inter-relacionados como: as condições climáticas vigentes e a química da água de poro (Morad et al. 2000), por exemplo, podem influenciar no desenvolvimento das alterações eodiagenéticas. Este é um novo campo de pesquisa nas geociências, o qual representa através da integração do estudo diagenético das rochas siliciclásticas com a estratigrafia de sequências, uma poderosa ferramenta de correlação estratigráfica.

Na região estudada, a história diagenética observada foi, inicialmente, marcada pela precipitação de bertierina na forma de cutículas e na forma de ooides (ironstone), pela posterior precipitação de siderita na forma de nódulos e como cimento, seguindo-se da precipitação de pirita e dolomita, e pela formação de raro crescimento secundário de quartzo. Por fim, ocorre a evolução da bertierina para chamosita; a cimentação da rocha por calcita e anquerita, a precipitação de óxido de titânio, e por último, a geração de porosidade secundária e precipitação de caolinita. Desses eventos diagenéticos, tanto a formação, quanto a distribuição dos ironstone, foram claramente controladas pela evolução estratigráfica da região ao longo do Meso-Neodevoniano, onde foi observada uma associação destes depósitos com as sequências de $4^{\mathrm{a}}$ ordem, sobretudo em função de sua acumulação abaixo das superfícies transgressivas de $4^{\mathrm{a}}$ ordem.

Por fim, os arenitos estudados na região de Dom Aquino (MT) apresentaram, especialmente no nível onde foram observados os ooides de bertierina (ironsto$n e$ ), uma boa porosidade (12\%). Essa porosidade estaria associada à dissolução telodiagenética. Assim, esse depósito particular pode ser um importante reservatório para um hipotético sistema petrolífero Ponta Grossa-Ponta Grossa, se considerarmos o potencial da Bacia do Paraná para geração de gás. 

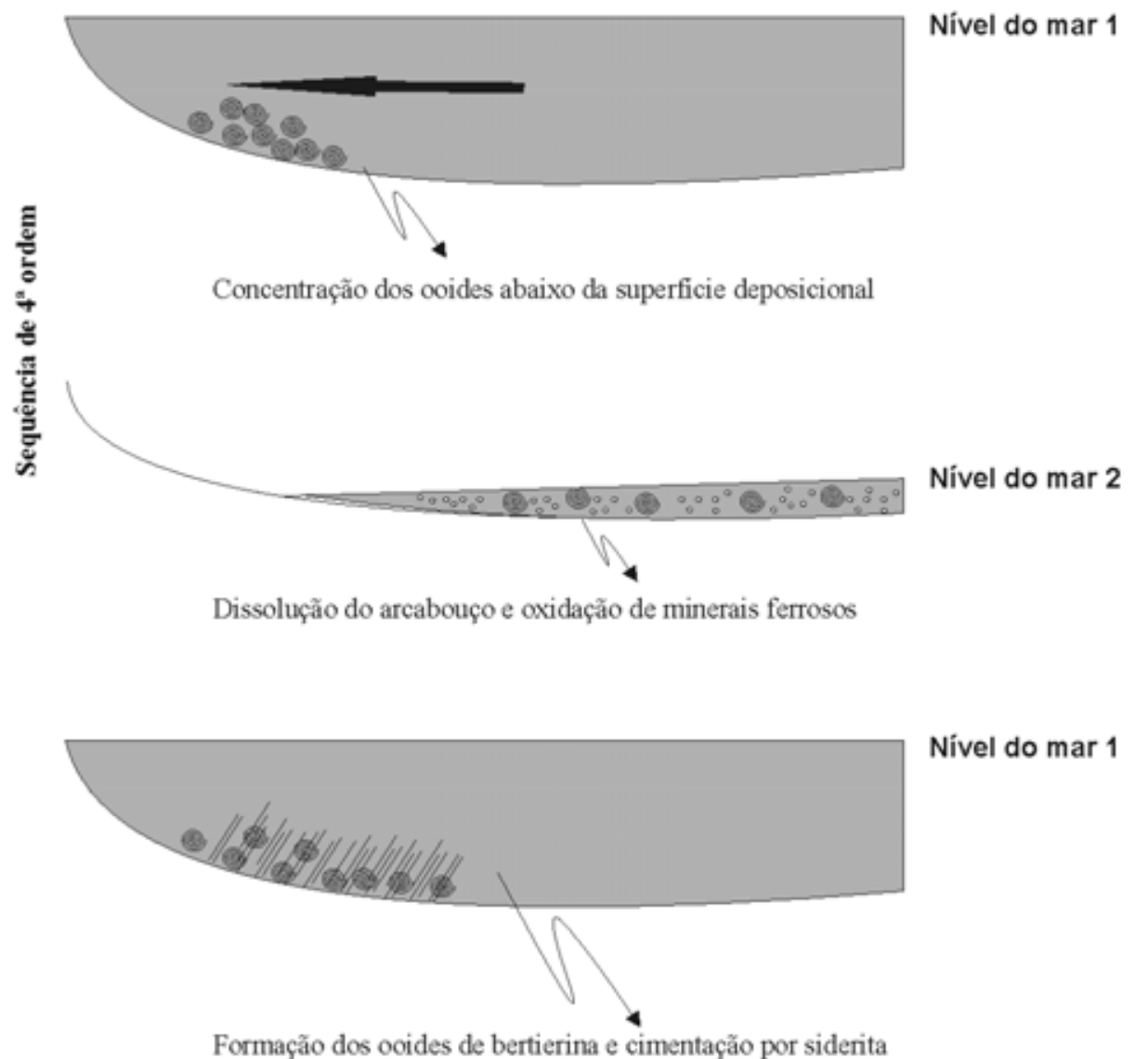

Nível do mar 1

Figura 10 - Modelo proposto para a formação dos ooides de bertierina no noroeste da Bacia do Paraná.

Agradecimentos À Agência Nacional do Petróleo (ANP) pela concessão de bolsa de mestrado ao primeiro autor; à FINEP pelo financiamento desta pesquisa; à Geóloga Fátima Andreia de Freitas Brazil (CENPES/PETROBRAS) pela colaboração nas descrições de lâminas petrográficas; à PETROBRAS pela disponibilização dos laboratórios de MEV e raios-X; ao Geólogo Sergio Brandolise Citroni (LAMM/ UFRRJ) no auxílio às análises remanescentes de difratometria de raios-X; o segundo autor agradece ao CNPq e à FAPERJ pelos auxílios recebidos para execução desta pesquisa.

\section{Referências}

Amorossi A. 1997. Detecting compositional, spatial, and temporal attributes of glaucony: a tool for provenance research. Sedimentary Geology, 109:135-153.

Assine M.L. 1996. Aspectos da estratigrafia das seqüencias pré-carboníferas da Bacia do Paraná no Brasil. Tese de Doutoramento, Instituto de Geociências, Universidade de São Paulo, São Paulo, 207 p.

Assine M.L., Fúlfaro V.J., Perinotto J.A.J., Petri S. 1998. Progradação deltaica Tibagi no devoniano médio da Bacia do Paraná. Rev. Bras. Geoc., 28(2):125-134.

Astini R.A. 1998. El Ordovícico de la región central del Famatina (provincia de La Rioja, Argentina): aspectos estratigráficos, geológicos y geotectónicos. Revista de la Asociación Geológica Argentina, 53(4):445-460.

Bergamaschi S. 1992. Análise sedimentológica da Formação Furnas na faixa de afloramentos do flanco norte do arco estrutural de Ponta Grossa, Bacia do
Paraná, Brasil. Dissertação de Mestrado. Instituto de Geociências, Universidade do Estado do Rio de Janeiro, Rio de Janeiro, 172 p.

Bergamaschi S. \& Pereira E. 2001. Caracterização de seqüências deposicionais de $3^{\mathrm{a}}$ ordem para o SiluroDevoniano na sub-bacia de Apucarana, bacia do Paraná, Brasil. In: Melo J.H.G. \& Terra G.J.S. (eds.) Correlações de Seqüencias Paleozóicas Sul-Americanas. Rio de Janeiro, Petrobras, p. 63-72.

Candido A.G. \& Rostirola S.P. 2008. Análise de fácies e revisão da estratigrafia de seqüências da Formação Ponta Grossa, Bacia do Paraná ênfase nos arenitos do Membro Tibagi. B. Geoci. Petrobras, 15(1):45-62.

Collin P.Y., Loreau J.P., Courville P. 2005. Depositional environments and iron ooid formation in condensed sections (Callovian-Oxfordian, south-eastern Paris basin, France). Sedimentology 52:969-985. 
Curtis C.D. 1985. Clay mineral precipitation and transformation during burial diagenesis. Philosophical Transactions of the Royal Society of London, A315:91105.

Deer W.A., Howie R.A., Zussman J. 1996. An Introduction to the Rock-Forming Minerals. 2.ed., London, Longman, $712 \mathrm{p}$.

Donaldson W.S., Plint A.G., Longstaffe F.J. 1999. Tectonic and eustatic control on deposition and preservation of Upper Cretaceous ooidal ironstone and associated facies: Peace River Arch area, NW Alberta, Canada. Sedimentology, 46:1159-1182.

Freitas-Brazil F.A. 2004. Estratigrafia de seqüencias e processo diagenético: exemplo dos arenitos marinhorasos da Formação Ponta Grossa, noroeste da Bacia do Paraná. Dissertação de Mestrado, Faculdade de Geologia, Universidade do Estado do Rio de Janeiro, Rio de Janeiro, 135 p.

Folk R.L. 1980. Petrology of sedimentary rocks. Austin, Hemphill Publishing Company, $182 \mathrm{p}$.

Fúlfaro V.J., Gama Jr. E., Soares P.C. 1980. Revisão estratigráfica da Bacia do Paraná. São Paulo, Paulipetro, $155 \mathrm{p}$.

Gaugris K.A. \& Grahn Y. 2006. New chitinozoan species from the Devonian of the Paraná Basin, south Brazil, and their biostratigraphic significance. Ameghiniana, 43(2):293-310.

Grahn Y., Bergamaschi S., Pereira E. 2002. Middle and Upper Devonian chitinozoan biostratigraphy of the Paraná Basin in Brazil and Paraguay. Palynology, 26:135-165.

Grahn Y., Mendlowicz Mauller P., Pereira E., Loboziak S. 2010a. Palynostratigraphy of the Chapada Group and its significance in the Devonian stratigraphy of the Paraná Basin, south Brazil. Journal of South American Earth Sciences, 29:354-370.

Grahn Y., Mendlowicz Mauller P., Breuer P., Bosetti E.P., Bergamaschi S., Pereira E. 2010b. The Furnas/Ponta Grossa contact and the age of the lowermost Ponta Grossa Formation in the Apucarana sub-basin (Paraná Basin, Brazil): integrated palynological age determination. Rev. Bras. Paleontol., 13(2):89-102.

Gygi, R.A., 1981, Oolitic iron formations: marine or not marine?: Eclogae Geologicae Helvetiae, 74:233-254.

Hallam, a. and Bradshaw, M. 1979. Bituminous shale and oolitic ironstones as indicators of regressions and transgressions. Journal of the Geological Society of London, 136: 157-164.

Lange F.W. \& Petri S. 1967. The Devonian of the Paraná Basin. Bol. Paranaense Geociências, 21/22:5-55.

Hornibrook E.R.C. \& Longstaffe F.J. 1996. Berthierine from the Lower Cretaceous Clearwater Formation, Alberta, Canada. Clays Clay Miner, 44:1-21.

Kearsley A.T. 1989. Iron-rich ooids, their mineralogy and microfabric: clues to their origin and evolution, In: Young T.P. \& Taylor W.E.G. (eds.) Phanerozoic Ironstones. London, Geological Society Special Publication, p. 141164.

Ketzer J.M. 2002. Diagenesis and sequence stratigraphy: an integrated approach to constrain evolution of reservoir quality in sandstone. Tese de Doutorado, Universidade de Uppsala, Uppsala, $30 \mathrm{p}$.

Ketzer J. M., Morad S., Amorossi A. 2003. Predictive diagenetic clay-mineral distribution in siliciclastic rocks within a sequence stratigraphy framework. In: Worden, R.H. \& Morad, S. (eds.) Clay Mineral Cements in Sandstones. Oxford, Int. Assoc. Sedimentol. Spec. Publ., p. 43-61.

Kimberley M.M. 1974. Origin of oolitic iron ore by diagenetic replacememt of calcareous oolite. Nature, 250:319-320.

Kimberley M.M. 1979, Origin of oolitic iron formations. Journal of Sedimentary Petrology, 49:111-132.

Melo J.H.G. 1988. The malvinokaffric realm in the Devonian of Brazil. In: McMillan N. J., Embry A.F., Glass D.J. (eds.) Devonian of the World. Calgary, Can. Soc. Petrol. Geol., p. 669-703.

Mendlowicz Mauller P. 2008. Bioestratigrafia do Devoniano da Bacia do Paraná - Brasil, com ênfase na Sub-bacia de Alto Garças. Tese de Doutorado, Faculdade de Geologia, Universidade do Estado do Rio de Janeiro, Rio de Janeiro, $141 \mathrm{p}$.

Milani E.J. 1997. Evolução tectono-estratigráfica da Bacia do Paraná e seu relacionamento com a geodinâmica fanerozóica do Gondwana Sul-Ocidental. Tese de Doutorado, Instituto de Geociências, Universidade Federal do Rio Grande do Sul, Porto Alegre, 254 p.

Milani E.J. 2004. Comentários sobre a origem e a evolução tectônica da Bacia do Paraná. In: Mantesso-Neto, V.; Bartorelli, A.; Carneiro, S. D. R.; Brito, B. B. N. (eds.) Geologia do continente sul-americano: evolução da obra de Fernando Flávio Marques de Almeida. São Paulo, Beca, p. 265-279.

Morad S., Ketzer J.M., De Ros L.F. 2000. Spatial and temporal distribution of diagenetic alterations in siliciclastic rocks: implications for mass transfer in sedimentary basins. Sedimentology, 47:95-120.

Odin G.S. 1988. Green Marine Clays - Developments in Sedimentology. Amsterdam, Elsevier, 444 p.

Oliveira A.S. \& Pereira E. 2008. Carbono orgânico total, gamaespectometria e bioturbação como ferramentas na identificação de possíveis horizontes geradores de hidrocarbonetos. In: IBP, Rio Oil \& Gas - Expo and Conference, 14, Anais, p. 1-8.

Oliveira L.C. 2009. Estudo das relações entre o arcabouço estratigráfico e as alterações diagenéticas observadas na seção Devoniana da Bacia do Paraná. Dissertação de Mestrado, Faculdade de Geologia, Universidade do Estado do Rio de Janeiro, Rio de Janeiro, 100 p.

Orcel, J., Hénin, S., and Caillère, S. 1949. Sur les silicates phylliteux des minerals de fer oolithiques. C.R. Acad. Sci. Paris, 229:134-135.

Orué D. 1996. Síntese da Geologia do Paraguai oriental, com ênfase para o magmatismo alcalino associado. Dissertação de Mestrado, Instituto de Geociências, Universidade de São Paulo, São Paulo, 163 p.

Pereira E. 2000. Evolução tectono-sedimentar do intervalo ordoviciano-devoniano da Bacia do Paraná com ênfase na Sub-Bacia de Alto Garças e no Paraguai oriental. Tese de Doutorado, Instituto de Geociências, Universidade de São Paulo, São Paulo, 276 p. 
Pereira E., Rodrigues R., Bergamaschi S., Pessôa de Souza M.S. 2010. Isotope Characterization of Late Devonian Flooding Surfaces in the Paraná Basin. In: SSAGI, South American Symposium on Isotope Geology, 7, Standard Abstract, p. 544-547.

Pessôa de Souza M.S. 2006. A Aplicação da Geoquímica Orgânica no Devoniano Médio/Superior da Borda Norte da Bacia do Paraná. Tese de Doutorado, Faculdade de Geologia, Universidade do Estado do Rio de Janeiro, Rio de Janeiro, $153 \mathrm{p}$.

Ramos A.N. 1970. Aspectos paleo-estruturais da Bacia do Paraná e sua influência na sedimentação. Rio de Janeiro. Boletim Técnico da Petrobras, 13:85-93.

Schneider R.L., Mühlmann H., Tommasi E., Medeiros R.A., Daemon R.F., Nogueira A.A. 1974. Revisão estratigráfica da Bacia do Paraná. In: SBG, Congresso Brasileiro de Geologia, 28, Anais, p. 41-65.

Siehl A. \& Thein J. 1989. Minette-type ironstones. In: Phanerozoic Ironstones (T.P. Young \& W.E.G. Taylor, editores). Geol. Soc. Spec. Publ., 46:175-193.

Sturesson U. 1995. Llanvirnian (Ord.) iron ooids in Baltoscandia: element mobility, REE distribution patterns, and origin of the REE. Chem. Geol., 125:45-60.

Sturesson U., Dronov A., Saadre T. 1999. Lower Ordovician iron ooids and associated oolitic clays in Russia and Estonia. Sedim. Geol., 123:63-80.

Sturesson U., Heikoop J.M., Risk M.J. 2000. Modern and Palaeozoic iron ooids - a similar volcanic origin. Sedim. Geol., 136:137-146.

Taylor K.G. \& Curtis C.D. 1995. Stability and facies association of early diagenetic mineral assemblages: an example from a Jurassic ironstone-mudstone succession. Journal of Sedimentary Research, A65:358-368.

Taylor K.G., Simo J.A., Yocum D., Leckie D.A. 2002. Stratigraphic significance of ooidal ironstones from the Cretaceous Western Interior Seaway: the Peace River Formation, Alberta, Canada, and the Castlegate Sandstone, Utah, U.S.A. Journal of Sedimentary Research, 72(2):316-327.

Van Houten F.B. 1982. Phanerozoic oolitic ironstones geologic record and facies model. Ann. Rev. Earth Planet. Sci., 10:441-457.

Velde B. 2003. Green Clay Minerals - Treatise on Geochemistry. Elsevier, 7:309-324.

Worden R.H. \& Morad S. 2003. Clay minerals in sandstone: controls on formation, distribution and evolution. In: R.H. Worden \& S. Morad (eds.) Clay Mineral Cements in Sandstones. Oxford, Blackwell Publishing, p. 3-41.

Young T.P. 1989. Eustatucally controlled ooidal ironstone deposition: facies relationships of the Ordovician openshelf ironstones of western Europe. In: Phanerozoic Ironstones (T.P. Young \& W.E.G. Taylor, editors). Geol. Soc. Spec. Publ., 46:51-64.

Young T.P. 1992. Ooidal ironstones from Ordovician Gondwana: a review. Palaeogeogr. Palaeoclimatol. Palaeoecol., 99:321-346.

Manuscrito ID 18064

Submetido em 31 de janeiro de 2011 Aceito em 13 de outubro de 2011 